\title{
Sequence of the superoxide dismutase 1 (SOD 1) gene in familial Parkinson's disease
}

\author{
O Bandmann, M B Davis, C D Marsden, A E Harding
}

\begin{abstract}
Mutations in the superoxide dismutase 1 (SOD1) gene have been detected in affected members of some families with familial amyotrophic lateral sclerosis. To evaluate the possibility of a shared genetic defect in amyotrophic lateral sclerosis and Parkinson's disease, the SOD1 gene was sequenced in index patients with familial Parkinson's disease from 23 families. No changes were detected.
\end{abstract}

(F Neurol Neurosurg Psychiatry 1995;59:90-91)

Keywords: Parkinson's disease; amyotrophic lateral sclerosis; superoxide dismutase

Oxidative stress, resulting from increased free radical production or defects in antioxidant systems, seems to play an important part in the pathogenesis of neurodegenerative diseases such as amyotrophic lateral sclerosis and Parkinson's disease. Oxidative stress in the substantia nigra in Parkinson's disease is indicated by increased concentrations of lipid hydroxyperoxides and decreased content of reduced glutathione. The increased concentration of iron and decreased concentration of ferritin in the substantia nigra might enhance free radical production. ${ }^{1}$ Enzymes such as superoxide dismutase (SOD) and glutathione peroxidase in brain normally prevent or limit tissue damage from oxidation derived free radicals. SOD 1 is a $\mathrm{Cu} / \mathrm{Zn}$ metalloenzyme that produces hydrogen peroxide by the dismutation of superoxide, a free radical. Rosen and colleagues ${ }^{2}$ showed that some patients with familial amyotrophic lateral sclerosis have mutations of the SOD1 gene. Mutations of SOD1 have since been detected in $13 \%$ to $20 \%$ of kindreds with familial amyotrophic lateral sclerosis; they are heterogeneous and occur in four of the five exons..$^{2-6}$ Intracellular SOD exists as two isoenzymes with different subcellular localisations. The major form, the copper/zinc-dependent SOD1, occurs largely in the cytosol, whereas the minor form, the manganese dependent SOD2, is found mainly in the mitochondrial matrix. Data on activity of SOD1 and SOD2 in the substantia nigra of patients with Parkinson's disease are conflicting. Some authors ${ }^{6}$ have found an increase in cytosolic, but not particulate, SOD activity, whereas others ${ }^{8}$ reported an increased activity of the particulate fraction with normal activity of the cytosolic form. Some, but not all, mutations of the SOD1 gene found in familial amyotrophic lateral sclerosis cause reduced enzyme activity. ${ }^{4}$

Amyotrophic lateral sclerosis and Parkinson's disease may occur in the same patient more often than would be expected by chance. ${ }^{9}$ There is also some evidence of nigrostriatal damage in amyotrophic lateral sclerosis. Positron emission tomography of patients with amyotrophic lateral sclerosis and no clinical signs of parkinsonism has shown a progressive fall in 6-fluorodopa uptake, and consistently reduced uptake in patients with amyotrophic lateral sclerosis of long duration. ${ }^{9}$ Cell loss in the substantia nigra has been observed in quantitative studies of amyotrophic lateral sclerosis brains. ${ }^{11}$

A shared genetic susceptibility for both amyotrophic lateral sclerosis and Parkinson's disease has been suggested. ${ }^{12}$ Amyotrophic lateral sclerosis and Parkinson's disease are clinically distinct, but mutations in different functional domains of SOD1 could result in phenotypic variation. Because transgenic mice with increased SOD1 activity show resistance to the neurotoxin N-methyl-4phenyl-1,2,3,6-tetrahydropyridine (MPTP), ${ }^{13}$ abnormal SOD1 activity in Parkinson's disease could result in increased susceptibility of dopaminergic neurons to neurotoxins such as MPTP.

Familial Parkinson's disease is not easily amenable to linkage analysis due to small family size and the possibility of genetic heterogeneity. To circumvent these problems, we have sequenced the SOD1 gene in 23 patients with familial Parkinson's disease to evaluate the possibility of a shared genetic defect in both familial amyotrophic lateral sclerosis and familial Parkinson's disease. Although a brief report suggested that mutations of this gene are not detected in sporadic cases of Parkinson's disease, ${ }^{14}$ they are also rare in sporadic amyotrophic lateral sclerosis. ${ }^{5}$ Exclusion of the SOD1 region by linkage analysis in three families with Parkinson's disease ${ }^{15}$ would not exclude a pathogenetic role of SOD1 mutations if, as is likely, there is substantial genetic heterogeneity as found in familial amyotrophic lateral sclerosis..$^{2-6}$ 


\section{Patients and methods}

PATIENTS

Blood samples were obtained from members of 23 British and Irish families, selected on the basis of the index case having clinically typical Parkinson's disease and at least one affected living relative. Nineteen of these families were reported previously, as were diagnostic criteria. ${ }^{16}$ The SOD1 coding region was entirely sequenced in one affected member of each family.

\section{METHODS}

DNA was extracted from blood by standard techniques. The five exons of the SOD1 gene were amplified with the polymerase chain reaction with the following primer pairs: $5^{\prime}$ TAA AGT AGT CGC GGA GAC GGG and 5' CGG CCT CGC AAC ACA AGC CT (exon 1), 5' GCA GTT AAG CAG CTT GCT GG and CCC ACC TGC TGT ATT ATC TCC (exon 2), 5' AAA TAG GCT GTA CCA GTG CA and 5' AGT GGT TGA CAG TAC TGT TC (exon 3), 5' CAT ATA GGC ATG TTG GAG ACT and 5' AGA GTT TAT CTG GAT CTT AG (exon 4), GTA TTG TTG GGA GGA GGT AGT GAT and 5' TTC TAC AGC TAG CAG GAT AAT (exon 5). Conditions for the polymerase chain reactions were: exon 1: one cycle at $92^{\circ}$ for three minutes, followed by 32 cycles of $92^{\circ}$ for one minute, $62^{\circ}$ for three minutes, and $72^{\circ}$ for two minutes; exons $2-5$ : one cycle at $92^{\circ}$ for three minutes, followed by 30 cycles of $92^{\circ}$ for 30 seconds, $58^{\circ}$ (exon 2), $57^{\circ}$ (exon 3 ), $45^{\circ}$ (exon 4 ), or $62^{\circ}$ (exon 5) for 30 seconds, and one cycle of $72^{\circ}$ for 30 seconds, followed by a final extension time of 10 minutes at $72^{\circ}$. Products of the polymerase chain reaction were purified with Magicprep (Promega) and rendered single stranded by capture on to streptavidin coated beads (Dynal). Direct sequencing was performed with fluorescent labelled dye terminators and an automated sequencer (Applied Biosystems). The internal primers used for sequencing were: 5' TTT CCG TTG CAG TCC TCG GAA (exon 1), 5' TTC AGA AAC TCT CTC CAA CTT TGC AC (exon 2), 5' CAC ATG AGT CAG CAA GTT CA (exon 3), 5' CGC GAC TAA CAA TCA AAG TG (exon 4), and 5' CAG TTT CTC ACT ACA GGT AC (exon 5). Sequences were compared with the published sequence (GenBank accession number: XO1662, XO1781-4).

\section{Results}

No changes were detected in the sequence of the SOD1 gene in any of the 23 index patients with familial Parkinson's disease.

\section{Discussion}

There is increasing evidence that there may be a genetic component in the pathogenesis of Parkinson's disease. There is an increased incidence of Parkinson's disease among the relatives of patients with Parkinson's disease, ${ }^{17}$ and large pedigrees apparently exhibiting autosomal dominant inheritance of Parkinson's disease have been described. ${ }^{18}$ Allelic association has been reported for the debrisoquine hydroxylase CYP2D6 locus, ${ }^{19}$ but this gene does not account for familial aggregation of Parkinson's disease. ${ }^{20}$ Our results show that changes in the coding region of the SOD1 gene, a reasonable candidate gene for familial Parkinson's disease, are unlikely to contribute to the pathogenesis of this disease.

We thank the Deutsche Forschungsgemeinschaft and the Parkinson's Disease Society (UK) for financial support, and our colleagues, particularly Dr DM Maraganore, for assistance in collecting samples.

1 Jenner P. Oxidative damage in neurodegenerative disease. Lancet 1994;344:796-8.

2 Rosen DR, Siddique T, Patterson D, et al. Mutations in $\mathrm{Cu} / \mathrm{Zn}$ superoxide dismutase gene are associated with familial amyotrophic lateral sclerosis. Nature 1993;362: $59-62$

3 Gurney ME, Pu H, Chiu AY, et al. Motor neuron degeneration in mice that express a human $\mathrm{Cu}, \mathrm{Zn}$ superoxide dismutase mutation. Science 1994;264:1772-5.

4 Borchelt DR, Lee MK, Slunt HS, et al. Superoxide dismutase 1 mutations linked to familial amyotrophic latmutase 1 mutations linked to familial amyotrophic latAcad Sci USA 1994;91:8292-6.

5 Jones CT, Brock DJH, Chancellor AM, Warlow CP, Swingler RI. Cu/Zn superoxide dismutase (SOD1) mutations and sporadic amyotrophic lateral sclerosis. Lancet 1993;342:1050-1.

6 Pramatarova A, Figlewicz DA, Krizius A, et al. Identification of new mutations in the $\mathrm{Cu} / \mathrm{Zn}$ superoxide dismutase gene of patients with familial amyotrophic lateral sclerosis. Am f Hum Genet 1995;56:592-6.

7 Marttila RJ, Lorentz H, Rinne UK. Oxygen toxicity protecting enzymes in Parkinson's disease. Increase of superoxide dismutase-like activity in the substantia nigra and basal nucleus. $\mathcal{F}$ Neurol $S c i 1988 ; 86: 321-31$.

8 Saggu H, Cooksey D, Dexter D, et al. A selective increase in particulate superoxide dismutase activity in in particulate superoxide dismutase activity in 692-7.

9 Eisen A, Calne D. Amyotrophic lateral sclerosis, Parkinson's disease and Alzheimer's disease: phylogenetic disorders of the human neocortex sharing many characteristics. Can $\mathcal{F}$ Neurol Sci 1992;19:117-20.

10 Takahashi H, Snow BJ, Bhatt MH, Peppard R, Eisen A, Calne DB. Evidence for a dopaminergic deficit in sporadic amyotrophic lateral sclerosis on positron emission scanning. Lancet 1993;342:1016-8.

11 Burrow JNC, Blumbergs PC. Substantia nigra degeneration in motor neuron disease: a quantitative study. Aust NZ $\mathcal{Y}$ Med 1992;22:469-72.

12 Majoor-Krakauer D, Otrman R, Johnson WG, Rowland LP. Familial aggregation of amyotrophic lateral sclerosis, dementia, and Parkinson's disease: evidence of shared genetic susceptibility. Neurology 1994;44:1872-7.
sharis

13 Przedborski S, Kostic V, Jackson-Lewis V, et al. Transgenic mice with increased Cu/Zn-superoxide dismutase activity are resistant to $\mathrm{N}$-methyl-4-phenyl1,2,3,6-tetrahydropyridine-induced neurotoxicity. $f$ Neuroscience 1992;12:1658-67.

14 Sapp PC, Fink JS, Horvitz HR, Brown RH. Screening of Parkinson's disease patients for mutations in superoxide dismutase. Society for Neuroscience Abstracts 1993;19: 403.

15 Gasser T, Wszolek ZK, Trofatter J, et al. Genetic linkage studies in autosomal dominant parkinsonism: evaluation of seven candidate genes. Ann Neurol 1994;36:387-96.

16 Maraganore DM, Harding AE, Marsden CD. A clinical and genetic study of familial Parkinson's disease. Mov Disord 1991;6:205-11.

17 Payami H, Larsen K, Bernard S, Nutt J. Increased risk of Parkinson's disease in parents and siblings of patients. Parkinson's disease in parents

18 Harding AE. Inherited movement disorders. In: Harding AE, ed. Genetics in neurology, Bailliere Tindall, 1994: 259-80.

19 Smith CAD, Gough AC, Leigh PN, et al. Association between CYP2D6-debrisoquine hydroxylase polymorphism and susceptibility to Parkinson's disease. Lancet 1992;339:1017-8.

20 Planté-Bordeneuve V, Davis MB, Maraganore DM, Marsden CD, Harding AE. Debrisoquine hydroxylase gene polymorphism in familial Parkinson's disease. $f$ Neurol Neurosurg Psychiatry 1994;57:911-3. 